\title{
Angiotensin-II receptor antagonist combined with calcium channel blocker or diuretic for essential hypertension
}

\author{
Toshihiko Ishimitsu, Atsushi Numabe, Toshihide Masuda, Tomoyuki Akabane, Atsushi Okamura, \\ Junichi Minami and Hiroaki Matsuoka
}

To achieve the target blood pressure recommended by the latest guidelines, multiple antihypertensive drugs are needed in most patients. In this study, the efficacy of treatment using an angiotensin II receptor antagonist (ARB) combined with a calcium channel blocker (CCB) or a diuretic was compared from multiple perspectives in patients with hypertension. Twenty-nine patients with essential hypertension, who had failed to achieve their target blood pressure $(<130 / 85 \mathrm{~mm} \mathrm{Hg}$ for patients $<65$ years old and $<140 / 90 \mathrm{~mm} \mathrm{Hg}$ for those $\geqslant 65$ years) when treated with the ARB olmesartan at $20 \mathrm{mg} \mathrm{day}^{-1}$, were additionally given 8-16 mg day ${ }^{-1}$ of the CCB azelnidipine or 1-2 $\mathrm{mg} \mathrm{day}^{-1}$ of trichlormethiazide (a thiazide diuretic) in a randomized crossover manner for 4 months each. At the end of each combination therapy period, blood and urine samples were collected and arterial stiffness was evaluated by measuring the cardio-ankle pulse wave velocity. Compared with monotherapy, the blood pressure was reduced similarly by adding azelnidipine $(-12 /-10 \mathrm{~mm} \mathrm{Hg})$ or trichlormethiazide $(-14 /-9 \mathrm{~mm} \mathrm{Hg})$. The heart rate was decreased with the CCB by 4 b.p.m. $(P<0.05)$, whereas it was unchanged with the thiazide. Serum $K$, lipids and blood glucose were not significantly changed with either combination, whereas serum uric acid was increased with the thiazide $(P<0.01)$ but was unchanged with azelnidipine. Plasma levels of renin, angiotensin II and aldosterone were also increased with the thiazide period, whereas high-sensitivity C-reactive protein and oxidized low-density lipoprotein were decreased with azelnidipine. In addition, the cardio-ankle vascular index, a parameter of arterial stiffness, was decreased with the azelnidipine period but was unchanged with the thiazide period $(P<0.01)$. It is suggested that the combination of olmesartan and azelnidipine has advantages over the combination of olmesartan and a thiazide with respect to avoiding hyperuricemia, sympathetic activation, renin-angiotensin-aldosterone system stimulation, inflammation, oxidative stress, and increased arterial stiffness in patients with moderate hypertension. These properties may provide cardiovascular protection in addition to the hypotensive effect.

Hypertension Research (2009) 32, 962-968; doi:10.1038/hr.2009.133; published online 21 August 2009

Keywords: angiotensin II receptor antagonist; calcium channel blocker; thiazide diuretic

\section{INTRODUCTION}

Epidemiological studies have indicated that there is a linear relationship between blood pressure and the risk of cardiovascular diseases such as stroke and myocardial infarction. This relationship also exists even in the normal blood pressure range below 140/90 $\mathrm{mm} \mathrm{Hg}$ down to $115 / 75 \mathrm{~mm} \mathrm{Hg}$. Therefore, the latest versions of various guidelines for the management of hypertension recommend a reduction of the blood pressure below the high end of the normal range, that is, lower than $130 / 85 \mathrm{~mm} \mathrm{Hg}$, in the non-elderly hypertensive patients. ${ }^{1-3}$ In particular, patients with complications such as diabetes mellitus and chronic kidney disease need stricter blood pressure control $(<130 /$ $80 \mathrm{~mm} \mathrm{Hg}$ ) to prevent the progression of target organ damage and to reduce the risk of cardiovascular disease.
However, only one-third of hypertensive patients achieve such target blood pressure levels with a single antihypertensive agent irrespective of the class of drug used and thus two-thirds of patients require a combination of two or more drugs to obtain adequate blood pressure reduction. ${ }^{4,5}$ When combining multiple antihypertensive drugs, the mechanism of action and adverse effects should be thoroughly understood to attain the maximum benefit from combination therapy. It is desirable for the antihypertensive effect to be enhanced and the adverse effects to be canceled by combining different classes of antihypertensive drugs.

In this randomized crossover study, the clinical efficacy of antihypertensive therapy combining an angiotensin II receptor antagonist (ARB) with a calcium channel blocker (CCB) or a thiazide diuretic was investigated in patients with moderate hypertension. 


\section{METHODS}

We enrolled a total of 50 outpatients with essential hypertension aged 30 to 79 years and classified as stage I or II according to the World Health Organization (WHO) criteria for organ damage. When not on medication, they had moderate hypertension (systolic blood pressure of $160-179 \mathrm{~mm} \mathrm{Hg}$ and/or diastolic blood pressure of $100-109 \mathrm{~mm} \mathrm{Hg}$ ) according to the classification in the Japanese Society of Hypertension Guidelines for the Management of Hypertension (JSH2004). ${ }^{6}$ Patients treated with a single antihypertensive agent could also be included if their blood pressure was not controlled at $<140$ / $90 \mathrm{~mm} \mathrm{Hg}$. Secondary causes of hypertension were ruled out through a comprehensive investigation. This study was performed in accordance with the recommendations of the World Medical Association for biomedical research involving human subjects (Edinburgh version, 2000), and was approved by the institutional review board. Informed consent was obtained from all subjects.

After stopping any current antihypertensive medications, the patients were treated with the ARB olmesartan at a dose of $20 \mathrm{mg}$ once daily in the morning for 1-3 months. The target blood pressure was $<130 / 85 \mathrm{~mm} \mathrm{Hg}$ for subjects younger than 65 years and $<140 / 90 \mathrm{~mm} \mathrm{Hg}$ for subjects aged 65 years or older. After the olmesartan monotherapy period, patients were assigned to combination therapy by a randomized crossover design if the target blood pressure was not achieved. Either $1 \mathrm{mg}$ of trichlormethiazide (a thiazide diuretic) once daily or $8 \mathrm{mg}$ of azelnidipine (a dihydropyridine CCB) once daily was added to olmesartan, after which combination therapy was continued for 4 months and the dose of trichlormethiazide or azelnidipine was increased to 2 and $16 \mathrm{mg}$, respectively, if the target blood pressure was not achieved. After 4 months of the initial combination therapy, trichlormethiazide was switched to azelnidipine and vice versa for a second period of combination therapy that continued for another 4 months. The order of the drugs was randomized. Blood pressure was measured by a sphygmomanometer at 2 - to 4 -week intervals with the patient in the sitting position after more than 20 min of rest.

At the end of each combination therapy period, a blood sample was taken from an antecubital vein after an overnight fast and $30 \mathrm{~min}$ of supine rest. In addition to a sample for routine biochemistry tests, part of the blood was placed into a chilled tube containing EDTA $\left(1 \mathrm{mg} \mathrm{ml}^{-1}\right)$. Plasma was separated by centrifugation at $4{ }^{\circ} \mathrm{C}$ and stored at $-80^{\circ} \mathrm{C}$ until assay. The plasma renin activity and plasma aldosterone concentration were determined by radioimmunoassay. Plasma angiotensin II was measured by direct radioimmunoassay using an Angiotensin II RIA kit (SRL, Tokyo, Japan). Plasma highsensitivity C-reactive protein (HSCRP), a marker of inflammation, was measured by a highly sensitive sandwich enzyme-linked immunosorbent assay. ${ }^{7}$ The plasma level of malondialdehyde-modified low-density lipoprotein (MDALDL), a marker of oxidative stress, was also measured by enzyme-linked immunosorbent assay. The estimated glomerular filtration rate (eGFR) was calculated from the serum creatinine $(\mathrm{sCr})$ concentration, and age by the following equation ${ }^{8}$ : eGFR $=194 \times \mathrm{Age}^{-0.287} \times \mathrm{sCr}^{-1.094}(\times 0.739$ for females $)$.

The first morning urine specimen was collected for urinalysis at the end of each combination therapy period. Urinary albumin was measured by an immunoturbidimetric method and expressed as a ratio to the urinary creatinine concentration.

To evaluate the effect of treatment on arterial stiffness, the cardio-ankle vascular index (CAVI) was measured with a Vasera VS-1000 system (Fukuda Denshi, Tokyo, Japan $)^{9,10}$ at the end of each combination therapy period.

Results are expressed as the mean \pm s.d. Clinical and laboratory data were compared between two groups by Student's $t$-test for paired samples. Comparisons between the three groups were performed by analysis of variance for repeated measures followed by the post hoc Tukey test. A $P$-value of less than 0.05 was considered to indicate statistical significance.

\section{RESULTS}

A total of 50 hypertensive patients who met the inclusion criteria started monotherapy with olmesartan at $20 \mathrm{mg}$ once daily. While receiving monotherapy, 21 patients achieved the target blood pressure $(<130 / 85 \mathrm{~mm} \mathrm{Hg}$ for patients younger than 65 years and $<140$ / $90 \mathrm{~mm} \mathrm{Hg}$ for patients aged 65 years or older). The remaining 29 patients were assigned to combination therapy in a randomized crossover manner. Table 1 lists the baseline characteristics of the 29 patients who received combination therapy. Eight patients had not been taking antihypertensive drugs and 21 patients had received a single antihypertensive agent earlier. Seven patients were taking a CCB before entering the study and six were taking an ARB, whereas a diuretic, angiotensin-converting enzyme inhibitor, $\beta$-blocker and $\alpha$ blocker were used by three, two, one and one patient, respectively. Twenty-two patients were younger than 65 years and seven patients were aged 65 years or older.

The average doses of azelnidipine and trichlormethiazide for combination therapy were $13 \pm 4$ and $1.6 \pm 0.5 \mathrm{mg}$, respectively. Figure 1 presents the time-course changes in blood pressure and pulse rate during the two combination therapy periods. Blood pressure was comparably lowered by the addition of azelnidipine or trichlormethiazide. Pulse rate was significantly reduced by azelnidipine, whereas it was rather increased by trichlormethiazide. Table 2 shows the physical findings of the 29 patients who received combination therapy at the end of each study period. The addition of azelnidipine or trichlormethiazide to olmesartan lowered the blood pressure to a similar extent in patients who had not achieved their target blood pressure on $20 \mathrm{mg}$ of olmesartan alone. The pulse rate was significantly lower in the combination therapy peiod with azelnidipine than in the monotherapy period, whereas it was not significantly changed in the period trichlormethiazide was added. Regarding the body weight, no significant change was observed throughout the study.

Table 3 lists the biochemistry data at the ends of the monotherapy period and each combination therapy period. Serum K, lipids and blood glucose were not significantly changed by either combination therapy. Serum insulin was not significantly changed either, but serum uric acid was significantly increased at the end of combined treatment with trichlormethiazide, whereas it was unchanged at the end of combined treatment with azelnidipine. Figure 2 shows the eGFR and urinary albumin excretion after each combination therapy. Neither of these parameters altered significantly throughout the monotherapy and combination therapy periods.

Figure 3 presents the plasma levels of renin activity, angiotensin II and aldosterone at the end of each study period. These components of the renin-angiotensin-aldosterone system (RAAS) were not significantly affected by the addition of azelnidipine to olmesartan; however, they were increased by combined treatment with trichlormethiazide compared with treatment with olmesartan alone. The left panel of Figure 4 shows the plasma level of HSCRP and the right panel shows plasma MDA-LDL. HSCRP (an inflammatory marker) was significantly lower during combined therapy with azelnidipine than with monotherapy, whereas the levels were comparable between the

\section{Table 1 Baseline characteristics of the subjects}

\begin{tabular}{lc}
\hline Age, (years) & $60 \pm 9$ \\
Gender, (male/female) & $14 / 15$ \\
Body mass index, $\left(\mathrm{kg} \mathrm{m}^{-2}\right.$ ) & $26.5 \pm 4.2$ \\
Systolic blood pressure, (mm Hg) & $149 \pm 15$ \\
Diastolic blood pressure, (mm Hg) & $94 \pm 10$ \\
Heart rate, (b.p.m.) & $72 \pm 9$ \\
Duration of hypertension, (years) & $16 \pm 10$ \\
WHO classification, (I/II) & $14 / 15$ \\
Habitual smoking, (+/-) & $6 / 18$ \\
Habitual alcohol intake, (+/-) & $12 / 17$
\end{tabular}

Data are the mean \pm s.d. 

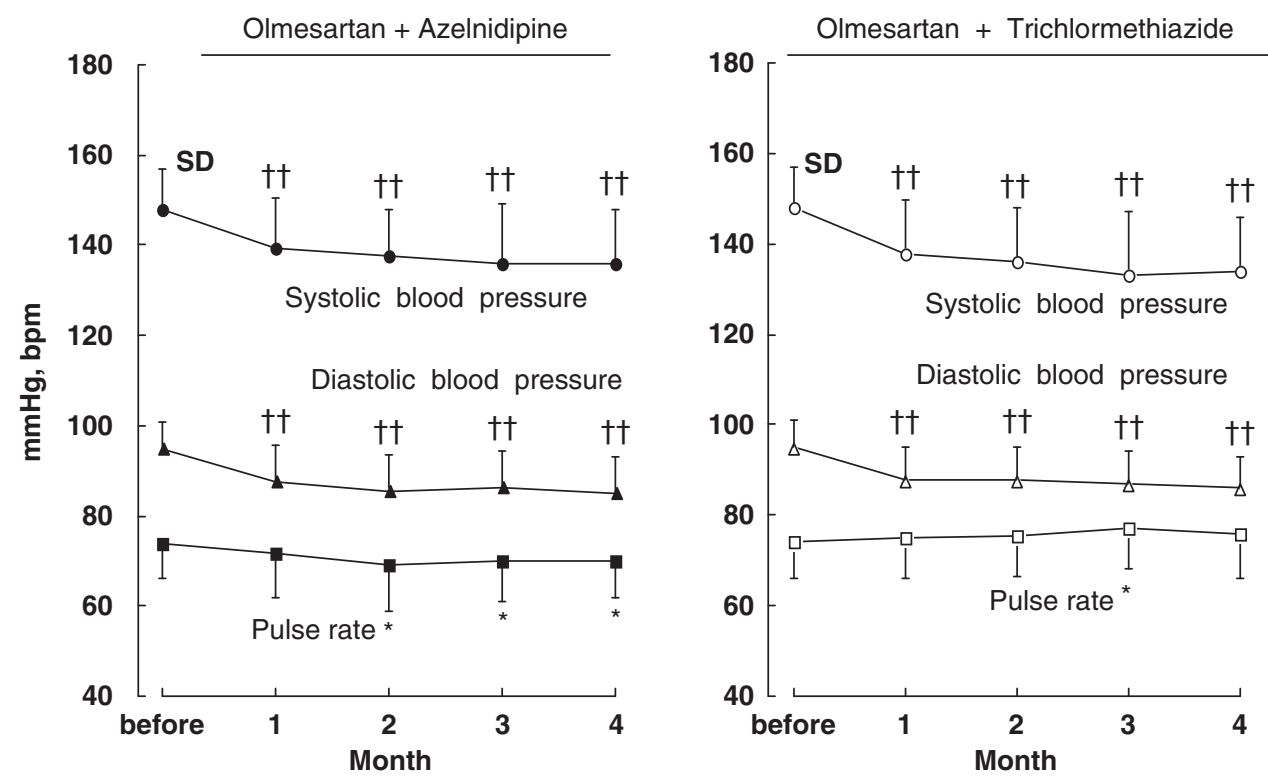

Figure 1 Time-course changes in blood pressure and pulse rate during the combination therapy period with azelnidipine or trichlormethiazide. ${ }^{*} P<0.05$, $\dagger P<0.001$ vs. the monotherapy period.

Table 2 Findings at the end of monotherapy and combination therapy

\begin{tabular}{lccc}
\hline Variable & Olmesartan alone & Olmesartan+azelnidipine & Olmesartan+trichlormethiazide \\
\hline Systolic blood pressure, $(\mathrm{mm} \mathrm{Hg})$ & $148 \pm 9$ & $136 \pm 12^{* *}$ & $134 \pm 12^{* *}$ \\
Diastolic blood pressure, $(\mathrm{mm} \mathrm{Hg})$ & $95 \pm 6$ & $85 \pm 8^{* *}$ & $86 \pm 7^{* *}$ \\
Pulse rate, (b.p.m.) & $74 \pm 8$ & $70 \pm 8^{*}$ & $76 \pm 10$ \\
Body weight, (kg) & $66.9 \pm 11.0$ & $66.9 \pm 11.7$ & $65.9 \pm 9.6$ \\
\hline
\end{tabular}

Data are the mean \pm s.d. ${ }^{*} P<0.05,{ }^{* *} P<0.001$ vs. monotherapy period with olmesartan.

Table 3 Biochemical data at the end of combined treatment with azelnidipine or trichlormethiazide

\begin{tabular}{|c|c|c|c|}
\hline Variable & Olmesartan alone & Olmesartan+azelnidipine & Olmesartan+trichlormethiazide \\
\hline Creatinine (mg per $100 \mathrm{ml}$ ) & $0.77 \pm 0.21$ & $0.76 \pm 0.19$ & $0.78 \pm 0.19$ \\
\hline Glucose, (mg per $100 \mathrm{ml}$ ) & $103 \pm 11$ & $103 \pm 10$ & $102 \pm 13$ \\
\hline Insulin, $\left(\mu \cup \mathrm{ml}^{-1}\right)$ & $12.4 \pm 7.5$ & $10.9 \pm 6.2$ & $10.3 \pm 4.1$ \\
\hline Total cholesterol, (mg per 100 ml) & $188 \pm 27$ & $191 \pm 30$ & $190 \pm 32$ \\
\hline Triglycerides, (mg per $100 \mathrm{ml}$ ) & $128 \pm 79$ & $143 \pm 83$ & $135 \pm 75$ \\
\hline
\end{tabular}

Data are the mean \pm s.d. ${ }^{*} P<0.01$ vs. monotherapy period with olmesartan.

combined therapy period with trichlormethiazide and the monotherapy period. Compared with the monotherapy period, plasma MDALDL, which reflects oxidized LDL, was also decreased with azelnidipine but was unchanged with the thiazide.

Cardio-ankle vascular index (an index of arterial stiffness) was lower at the end of combined treatment with azelnidipine than with monotherapy but was not significantly different between the combined treatment with trichlormethiazide and monotherapy, which means that arterial stiffness was reduced by the addition of azelnidipine but not by the addition of trichlormethiazide (Figure 5).

\section{DISCUSSION}

In this study of patients with moderate hypertension, $42 \%$ of the subjects reached the target blood pressure on an average dose of olmesartan alone. This result agrees with earlier reports that the antihypertensive effect of olmesartan is greater to other ARBs. ${ }^{11,12}$ Thiazide diuretics are not only inexpensive first-line therapy for hypertension but are also effective when combined with other classes of antihypertensive drugs, because thiazides promote the urinary excretion of $\mathrm{Na}$, which is retained because of vasodilation and suppression of cardiac function by other antihypertensive drugs. 

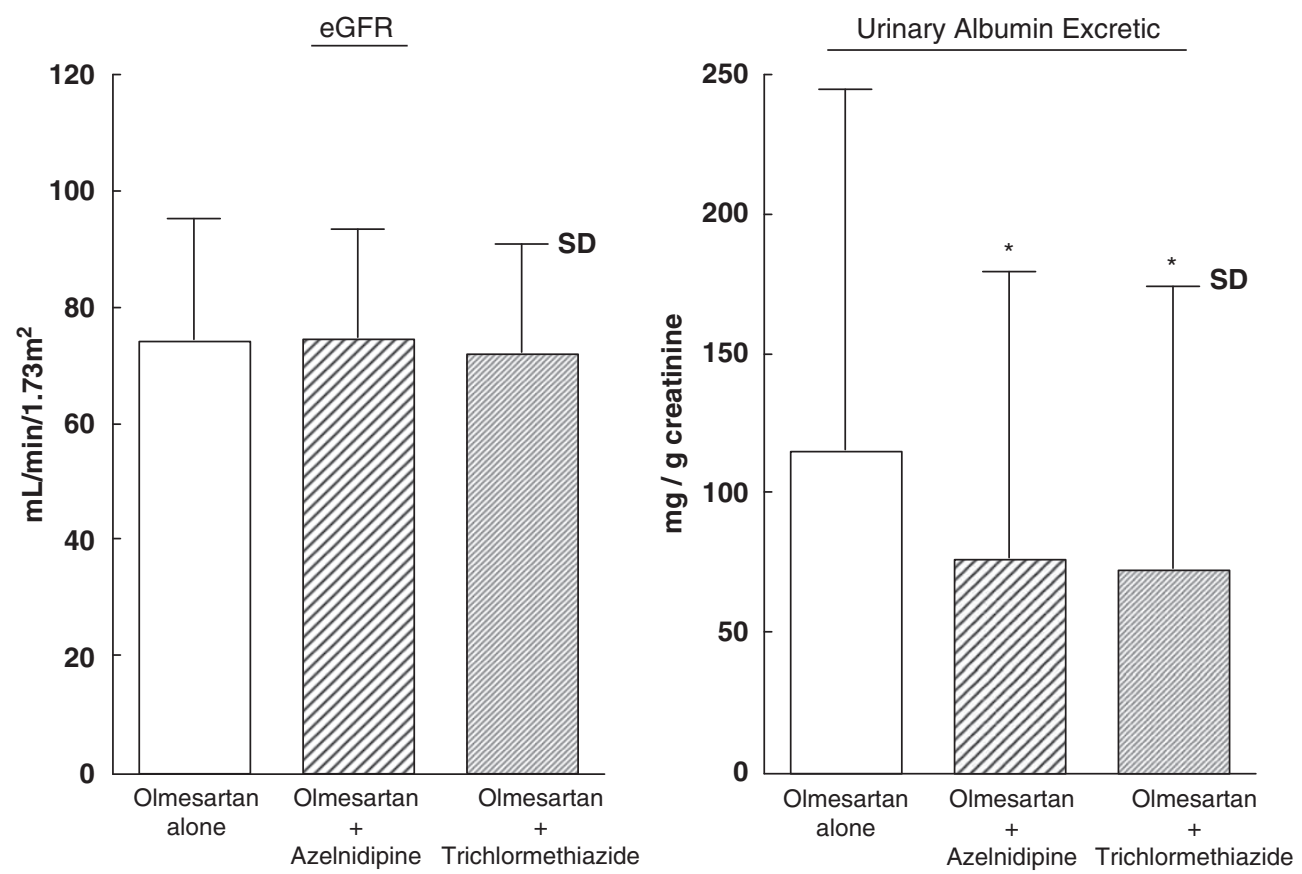

Figure 2 Estimated glomerular filtration rate (eGFR) and urinary albumin excretion at the end of each combination therapy. ${ }^{*} P<0.05$ vs. the monotherapy period.
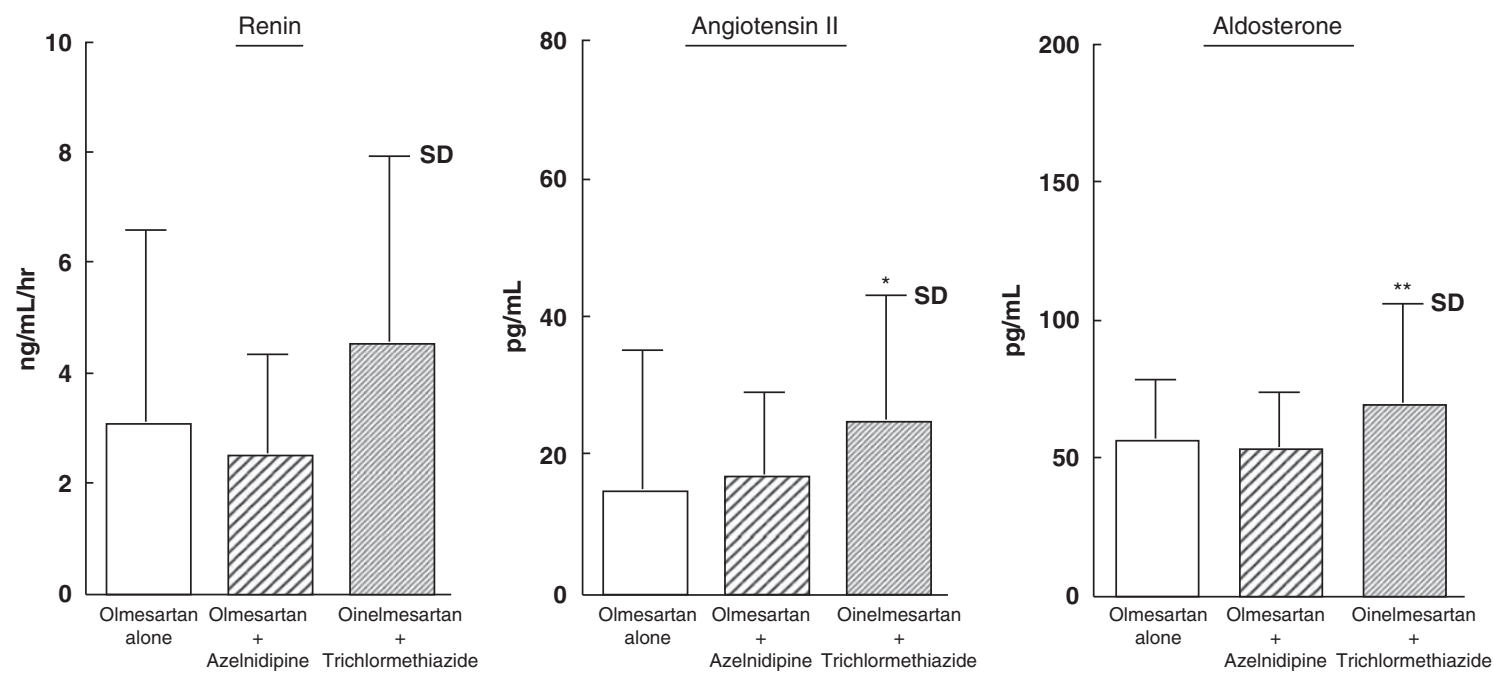

Figure 3 Plasma renin activity and plasma concentrations of angiotensin II and aldosterone at the end of each combination therapy. ${ }^{*} P<0.05,{ }^{*} P<0.01$ vs. the monotherapy period.

The hypotensive effect is expected to be increased synergistically by the combination of a diuretic and an ARB, because ARBs block the upregulation of RAAS by diuretics in response to a decrease of body fluid volume. However, thiazide diuretics can possibly cause adverse metabolic effects, including hypokalemia, hyperuricemia, dyslipidemia and impaired glucose tolerance. These adverse effects of diuretics can be potentially ameliorated by ARBs, which improve insulin resistance and increase plasma $\mathrm{K}$ levels. In this study, serum glucose, lipids and $\mathrm{K}$ were not significantly different between trichlormethiazide and azelnidipine therapy, although the serum uric acid level was higher with the thiazide than with the CCB. Hyperuricemia may prevent the continuation of thiazide therapy even when combined with an ARB, but other adverse effects of thiazides seem to be alleviated by RAAS inhibitors.
As CCBs directly dilate the vascular smooth muscle, their hypotensive effect is consistent and dose-dependent. In addition, CCBs and ARBs rarely cause severe adverse effects in hypertensive patients. Therefore, the combination of an ARB and a CCB is not only effective, but also safe, for long-term antihypertensive therapy. With respect to the occurrence of adverse effects, the results of this study suggested that the $A R B+C C B$ combination is greater to the ARB+thiazide combination in terms of not increasing the serum uric acid level.

Pulse wave velocity is an indicator of arterial stiffness and an increased pulse wave velocity has been shown to reflect a higher risk of cardiovascular disease. ${ }^{13,14}$ However, it has been pointed out that the pulse wave velocity varies according to the changes of blood pressure and sympathetic activity. ${ }^{15,16}$ CAVI was measured in this study, and it is calculated by adjusting pulse wave velocity for blood 

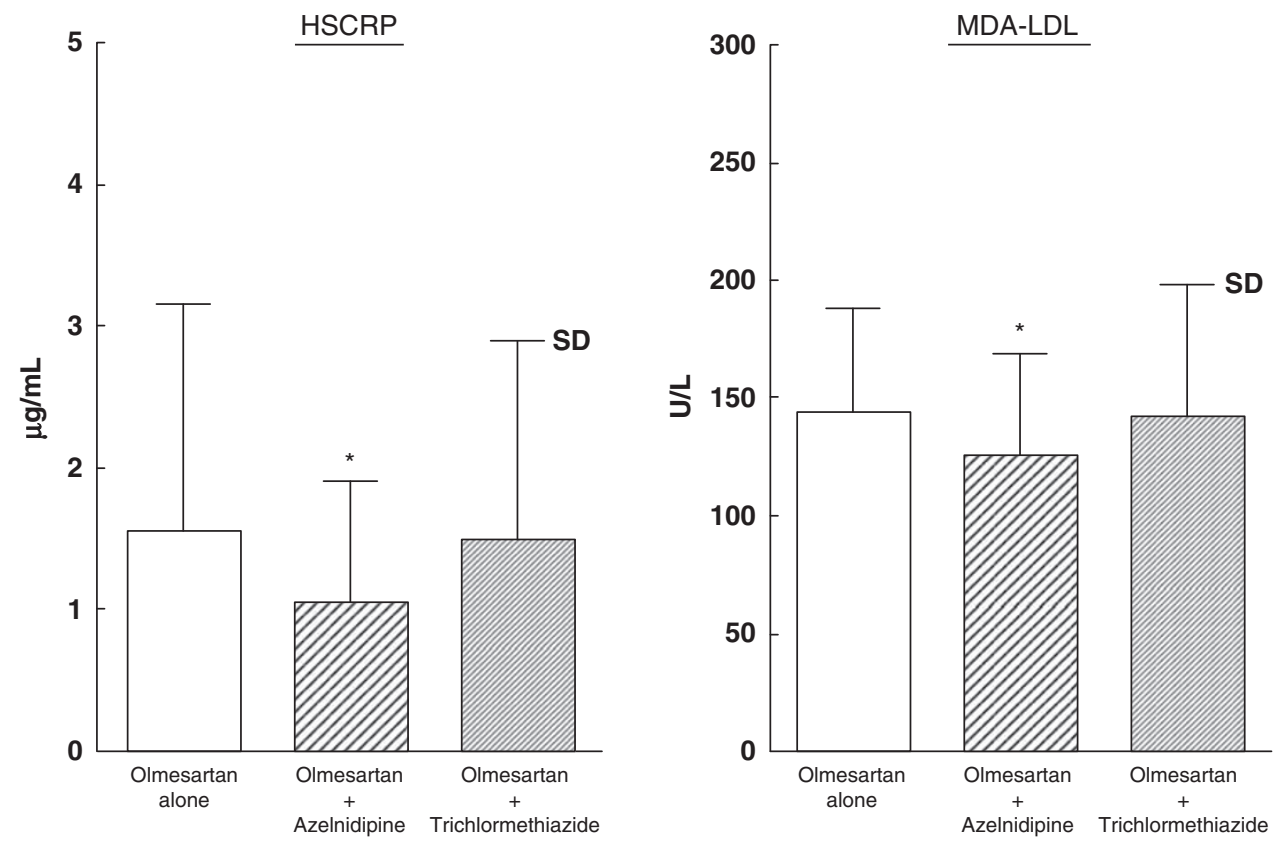

Figure 4 Plasma levels of high-sensitivity C-reactive protein (HSCRP) and malondialdehyde-modified low-density lipoprotein (MDA-LDL) at the end of each combination therapy. ${ }^{*} P<0.05$ vs. the monotherapy period.

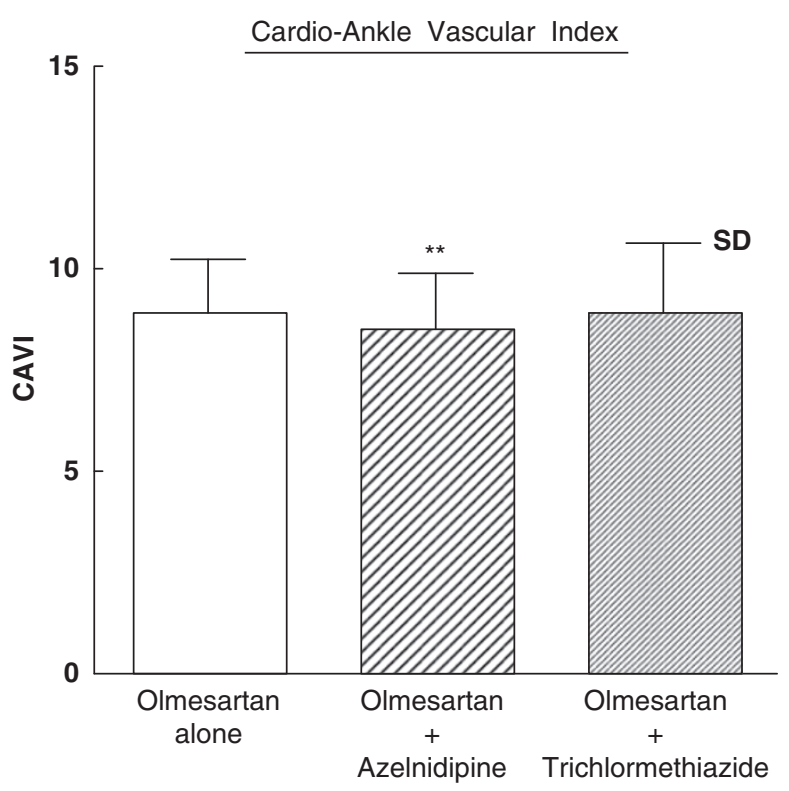

Figure 5 Cardio-ankle vascular index (CAVI) at the end of each combination therapy. ${ }^{*} P<0.01$ vs. the monotherapy period.

pressure based on a stiffness parameter (b). Thus, it is thought to be a more accurate index of arterial stiffness. ${ }^{9} 10$ In this study, CAVI was lower with azelnidipine than with trichlormethiazide period, which suggests that the CCB was more effective at reducing arterial stiffness than the thiazide diuretic. In most studies investigating the effects of antihypertensive drugs on arterial stiffness, the parameter was evaluated after treating for 6 months or more. ${ }^{17}$ The treatment periods of this study were shorter than this and may be insufficient to cause the structural changes in arterial walls. Theoretically, CCBs should reduce arterial stiffness by relaxing the arterial smooth muscle, whereas the blood volume reduction caused by diuretic therapy could lead to an increase in vascular resistance. Therefore, such functional difference in the effects on the arterial tension between CCB and diuretics may have resulted in the reduction of CAVI in the combination therapy with azelnidipine and the lack of such effect in the combination therapy with trichlormethiazide.

Among the various components of the RAAS, angiotensin II enhances the production of free radicals, promotes cell growth, and increases the synthesis of inflammatory and profibrotic cytokines. ${ }^{18,19}$ Recent studies have revealed that aldosterone also promotes free radical production and endothelial dysfunction, as well as having mitogenic and profibrotic actions. ${ }^{20,21}$ These nonhemodynamic effects of angiotensin II and aldosterone are deleterious to the cardiovascular system and cause inflammation, fibrosis and scarring of various tissues that lead to cardiovascular organ dysfunction and increase the incidence of cardiovascular disease. In this study, circulating RAAS factors, such as angiotensin II and aldosterone, were increased by the thiazide compared with the CCB. Although the RAAS in cardiovascular tissues may not always show a parallel response to circulating hormone levels, RAAS upregulation by thiazide therapy could possibly have an adverse influence on the development of cardiovascular organ damage in hypertensive patients. The average plasma renin activity was not markedly high during the monotherapy period even though the ARB was administered. A considerable part of the patients of this study, 19 out of 29, showed signs of renal injury such as eGFR less than $60 \mathrm{ml} \mathrm{min}^{-1}$ per $1.73 \mathrm{~m}^{2}$ and albuminuria, although their $\mathrm{sCr}$ levels were within normal range, $<1.2 \mathrm{mg}$ per $100 \mathrm{ml}$ for men and $<1.0 \mathrm{mg}$ per $100 \mathrm{ml}$ for women. Therefore, the increase in plasma renin activity by olmesartan may not be prominent in the existence of low renin hypertension because of renal impairment. In addition, plasma aldosterone concentration was significantly increased by trichlormethiazide, although the angiotensin II type 1 receptor had been blocked by olmesartan. Considering that the hypotensive effect of olmesartan has been shown to increase dose-dependently up to $80 \mathrm{mg}$, 
the dose of $20 \mathrm{mg}$ used in this study did not fully block the angiotensin II type 1 receptors and allowed an increase in aldosterone by stimulation with a diuretic.

Cardiovascular disease arises because of the progression of arteriosclerosis. Laboratory and experimental evidence has indicated that chronic inflammation has a role in the development of arteriosclerosis. $^{22,23}$ A number of studies have examined various circulating markers of inflammation, such as cytokines and adhesion molecules, as potential predictors of the existence and future risk of cardiovascular disease. Among the numerous circulating markers studied thus far, HSCRP seems to have the most consistent relation with the risk of cardiovascular diseases in a variety of clinical settings including hypertension. ${ }^{24-26}$ In addition to the classical risk factors for arteriosclerosis, such as hypertension and dyslipidemia, oxidative stress has been attracting considerable attention as one of the novel risk factors for cardiovascular injury. Oxidative stress depletes nitric oxide and causes endothelial dysfunction that initiates arteriosclerosis. Oxidized LDL generated by oxidative stress also promotes the progression of arteriosclerosis. $^{27-29}$ In this study, plasma HSCRP and MDA-LDL levels were lower with azelnidipine than with thiazide therapy. The antioxidant effect of azelnidipine possibly participated in the reduction of plasma MDA-LDL levels. ${ }^{30,31}$ With regard to the changes in HSCRP, the anti-inflammatory effects of CCB seem variable; ${ }^{32}$ however, it has been reported that azelnidipine, but not nifedipine, reduced plasma inflammatory markers in patients with diabetic nephropathy. ${ }^{33}$ Therefore, azelnidipine seems more effective in alleviating oxidative stress and inflammation than other dihydropyridine CCBs.

Epidemiological studies have indicated that an increased heart rate is associated with a higher incidence of cardiovascular diseases and a worse prognosis. ${ }^{34-36}$ Tachycardia caused by reflex activation of the sympathetic nervous system is one of the major adverse effects of CCB therapy. Unlike other dihydropyridine CCBs, however, azelnidipine has been shown to inhibit sympathetic activity. ${ }^{37}$ On the contrary, natriuresis and the decrease of body fluid volume caused by diuretics are considered likely to increase sympathetic activity and the heart rate. In this study, the heart rate was lower during azelnidipine therapy than with thiazide therapy. This property of azelnidipine may be beneficial for the inhibition of cardiovascular events in hypertensive patients.

The ACCOMPLISH study ${ }^{38}$ compared benazepril+amlodipine and benazepril+hydrochlorothiazide in high-risk hypertensive patients, and found fewer cardiovascular events with the former combination than with the latter. On the other hand, the GUARD study ${ }^{39}$ examined the combination of an angiotensin-converting enzyme inhibitor with a CCB or thiazide diuretic in type II diabetic patients and showed that the thiazide was greater to the $\mathrm{CCB}$ with regard to reducing albuminuria. In this study, renal parameters such as eGFR and urinary albumin excretion did not differ significantly between azelnidipine and trichlormethiazide combined with an ARB. Thus, the long-term effects of combined antihypertensive therapy on the kidneys need to be evaluated in further clinical trials. It may be worth noting that azelnidipine has been shown to reduce proteinuria more effectively than amlodipine in patients with chronic kidney disease. ${ }^{40}$

In summary, this study showed that the combination of olmesartan and azelnidipine was greater to the combination of olmesartan and trichlormethiazide with regard to avoiding hyperuricemia, reflex sympathetic activation, RAAS upregulation, inflammation, oxidative stress, and increased arterial stiffness in patients with moderate hypertension who required combination therapy. The combination therapy with olmesartan and azelnidipine may provide better cardio- vascular organ protection than the combination therapy with olmesartan and a thiazide in addition to its hypotensive effect. However, care should be taken in interpreting the results of this study because the study protocol does not correspond with the practical treatment in some respects. First, the dose of trichlormethiazide was increased to achieve further blood pressure reduction, although the use of highdose diuretics is not recommended in terms of preventing coronary heart disease. ${ }^{41,42}$ Second, olmesartan was used in a single dose; however, the increase in the dose of ARB may be a choice of treatment to intensify the antihypertensive effect.

1 Chobanian AV, Bakris GL, Black HR, Cushman WC, Green LA, Izzo Jr JL, Jones DW, Materson BJ, Oparil S, Wright Jr JT, Roccella EJ. The Seventh Report of the Joint National Committee on Prevention, Detection, Evaluation, and Treatment of High Blood Pressure: the JNC 7 report. JAMA 2003; 289: 2560-2572.

2 The Task Force for the Management of Arterial Hypertension of the European Society of Hypertension (ESH) and of the European Society of Cardiology (ESC). 2007 Guidelines for the management of arterial hypertension. Eur Heart J 2007; 28: 1462-1536.

3 The Japanese Society of Hypertension Committee for Guidelines for the Management of Hypertension. The Japanese Society of Hypertension Guidelines for the Management of Hypertension (JSH 2009). Hypertens Res 2009; 32: 3-107.

4 Elliott WJ. Is fixed combination therapy appropriate for initial hypertension treatment? Curr Hypertens Rep 2002; 4: 278-285.

5 Mori H, Ukai H, Yamamoto H, Saitou S, Hirao K, Yamauchi M, Umemura S. Current status of antihypertensive prescription and associated blood pressure control in Japan. Hypertens Res 2006; 29: 143-151.

6 Japanese Society of Hypertension. Japanese Society of Hypertension guidelines for the management of hypertension (JSH 2004). Hypertens Res 2006; 29 (Suppl): S1-S105.

7 Saito M, Ishimitsu T, Minami J, Ono H, Ohrui M, Matsuoka H. Relations of plasma highsensitivity C-reactive protein to traditional cardiovascular risk factors. Atherosclerosis 2003; 167: 73-79.

8 Matsuo S, Imai E, Horio M, Yasuda Y, Tomita K, Nitta K, Yamagata K, Tomino Y, Yokoyama $\mathrm{H}$, Hishida A. Revised equations for estimated GFR from serum creatinine in Japan. Am J Kidney Dis 2009; 53: 982-992.

9 Shirai K, Utino J, Otsuka K, Takata M. A novel blood pressure-independent arterial wall stiffness parameter; cardio-ankle vascular index (CAVI). J Atheroscler Thromb 2006; 13: 101-107.

10 Takaki A, Ogawa H, Wakeyama T, Iwami T, Kimura M, Hadano Y, Matsuda S, Miyazaki Y, Hiratsuka A, Matsuzaki M. Cardio-ankle vascular index is superior to brachial-ankle pulse wave velocity as an index of arterial stiffness. Hypertens Res 2008; 31: 1347-1355

11 Smith DH, Dubiel R, Jones M. Use of 24-hour ambulatory blood pressure monitoring to assess antihypertensive efficacy: a comparison of olmesartan medoxomil, losartan potassium, valsartan, and irbesartan. Am J Cardiovasc Drugs 2005; 5: 41-50.

12 Oparil S, Williams D, Chrysant SG, Marbury TC, Neutel J. Comparative efficacy of olmesartan, losartan, valsartan, and irbesartan in the control of essential hypertension. J Clin Hypertens 2001; 3: 283-291.

13 Zoungas S, Asmar RP. Arterial stiffness and cardiovascular outcome. Clin Exp Pharmacol Physiol 2007; 34: 647-651.

14 London GM, Marchais SJ, Guerin AP, Pannier B. Arterial stiffness: pathophysiology and clinical impact. Clin Exp Hypertens 2004; 26: 689-699.

15 Matsui Y, Kario K, Ishikawa J, Eguchi K, Hoshide S, Shimada K. Reproducibility of arterial stiffness indices (pulse wave velocity and augmentation index) simultaneously assessed by automated pulse wave analysis and their associated risk factors in essential hypertensive patients. Hypertens Res 2004; 27: 851-857.

16 Ito N, Ohishi M, Takagi T, Terai M, Shiota A, Hayashi N, Rakugi H, Ogihara T. Clinical usefulness and limitations of brachial-ankle pulse wave velocity in the evaluation of cardiovascular complications in hypertensive patients. Hypertens Res 2006; 29 : 989-995.

17 Asmar R. Effect of antihypertensive agents on arterial stiffness as evaluated by pulse wave velocity: clinical implications. Am J Cardiovasc Drugs 2001; 1: 387-397.

18 Struthers AD, MacDonald TM. Review of aldosterone- and angiotensin II-induced target organ damage and prevention. Cardiovasc Res 2004; 61: 663-670.

19 Schmieder RE, Hilgers KF, Schlaich MP, Schmidt BM. Renin-angiotensin system and cardiovascular risk. Lancet 2007; 369: 1208-1219.

20 Hostetter TH, Ibrahim HN. Aldosterone in chronic kidney and cardiac disease. J Am Soc Nephrol 2003; 14: 2395-2401.

21 Marney AM, Brown NJ. Aldosterone and end-organ damage. Clin Sci 2007; 113 : 267-278.

22 Ross R. Atherosclerosis-an inflammatory disease. N Engl J Med 1999; 340: $115-126$.

23 Jialal I, Devaraj S. Inflammation and atherosclerosis: the value of the high-sensitivity C-reactive protein assay as a risk marker. Am J Clin Pathol 2001; 116 (Suppl): S108-S115. 
24 Kuller LH, Tracy RP, Shaten J, Meilahn EN. Relation of C-reactive protein and coronary heart disease in the MRFIT nested case-control study. Multiple Risk Factor Intervention Trial. Am J Epidemiol 1996; 144: 537-547.

25 Schillaci G, Pirro M. C-reactive protein in hypertension: clinical significance and predictive value. Nutr Metab Cardiovasc Dis 2006; 16: 500-508.

26 Hage FG, Szalai AJ. C-reactive protein gene polymorphisms, C-reactive protein blood levels, and cardiovascular disease risk. J Am Coll Cardiol 2007; 50: 1115-1122.

27 Steinberg D, Parthasarathy S, Carew TE, Khoo JC, Witztum JL. Beyond cholesterol. Modifications of low-density lipoprotein that increase its atherogenicity. N Engl J Med 1989; 320: 915-924.

28 Witztum JL, Steinberg D. Role of oxidized low density lipoprotein in atherogenesis. J Clin Invest 1991; 88: 1785-1792.

29 Mertens A, Holvoet P. Oxidized LDL and HDL: antagonists in atherothrombosis. FASEB J 2001; 15: 2073-2084.

30 Nada T, Nomura M, Koshiba K, Kawano T, Mikawa J, Ito S. Clinical study with azelnidipine in patients with essential hypertension. Antiarteriosclerotic and cardiac hypertrophy-inhibitory effects and influence on autonomic nervous activity. Arzneimittelforschung 2007; 57: 698-704.

31 Ohmura C, Watada H, Shimizu T, Sakai K, Uchino H, Fujitani Y, Kanazawa A, Hirose T, Kawamori R. Calcium channel blocker, azelnidipine, reduces lipid hydroperoxides in patients with type 2 diabetes independent of blood pressure. Endocr J 2007; 54. 805-811.

32 Prasad K. C-reactive protein (CRP)-lowering agents. Cardiovasc Drug Rev 2006; 24: 33-50.

33 Ogawa S, Mori T, Nako K, Ito S. Combination therapy with renin-angiotensin system inhibitors and the calcium channel blocker azelnidipine decreases plasma inflammatory markers and urinary oxidative stress markers in patients with diabetic nephropathy. Hypertens Res 2008; 31: 1147-1155.
34 Neutel JM. Clinical studies of CS-866, the newest angiotensin II receptor antagonist. Am J Cardiol 2001; 87 (8A): 37C-43C.

35 Püchler K, Laeis P, Stumpe KO. Blood pressure response, but not adverse event incidence, correlates with dose of angiotensin II antagonist. J Hypertens Supp/ 2001; 19: S41-S48.

36 Gillman MW, Kannel WB, Belanger A, D'Agostino RB. Influence of heart rate on mortality among persons with hypertension: the Framingham Study. Am Heart J 1993; 125: 1148-1154.

37 Seccareccia F, Pannozzo F, Dima F, Minoprio A, Menditto A, Lo Noce C, Giampaoli S. Heart rate as a predictor of mortality: the MATISS project. Am J Public Health 2001; 91: 1258-1263.

38 Hozawa A, Ohkubo T, Kikuya M, Ugajin T, Yamaguchi J, Asayama K, Metoki H, Ohmori $\mathrm{K}$, Hoshi H, Hashimoto J, Satoh H, Tsuji I, Imai Y. Prognostic value of home heart rate for cardiovascular mortality in the general population: the Ohasama study. Am J Hypertens 2004; 17: 1005-1010.

39 Konno S, Hirooka Y, Araki S, Koga Y, Kishi T, Sunagawa K. Azelnidipine decreases sympathetic nerve activity via antioxidant effect in the rostral ventrolateral medulla of stroke-prone spontaneously hypertensive rats. J Cardiovasc Pharmacol 2008; 52: 555-560.

40 Jamerson K, Weber MA, Bakris GL, Dahlöf B, Pitt B, Shi V, Hester A, Gupte J, Gatlin M, Velazquez EJ. Benazepril plus amlodipine or hydrochlorothiazide for hypertension in high-risk patients. N Engl J Med 2008; 359: 2417-2428.

41 Bakris GL, Toto RD, McCullough PA, Rocha R, Purkayastha D, Davis P. Effects of different ACE inhibitor combinations on albuminuria: results of the GUARD study. Kidney Int 2008; 73: 1303-1309.

42 Nakamura T, Sugaya T, Kawagoe Y, Suzuki T, Ueda Y, Koide H, Inoue T, Node K. Azelnidipine reduces urinary protein excretion and urinary liver-type fatty acid binding protein in patients with hypertensive chronic kidney disease. Am J Med Sci 2007; 333: 321-326. 